\title{
Diagnosis of Fucosidosis through Cutaneous Manifestations
}

\author{
Bouguila Jihene1* ${ }^{*}$ Mabrouk Sameh', Ben Turkia Hadhemi'2, Mokni Mourad³, \\ Boughammoura Lamia1 \\ ${ }^{1}$ Department of Pediatrics, Hospital Farhat Hached, Sousse, Tunisia \\ ${ }^{2}$ Department of Pediatrics, Hospital La Rabta, Tunis, Tunisia \\ ${ }^{3}$ Department of Dermatology, Hospital La Rabta, Tunis, Tunisia \\ Email: jbouguila@yahoo.fr
}

Received 1 September 2013; revised 2 October 2013; accepted 18 October 2013

Copyright (C) 2014 by authors and Scientific Research Publishing Inc.

This work is licensed under the Creative Commons Attribution International License (CC BY).

http://creativecommons.org/licenses/by/4.0/

(c) (i) Open Access

\begin{abstract}
Angiokeratoma corporis diffusum is a dermatological hallmark of several inherited lysosomal storage disorders including Anderson-Fabry disease and other enzyme deficiencies such as fucosidosis. We report a 4-year-old boy with neurodevelopment delay who was diagnosed as having fucosidosis following recognition of dermatological signs, angiokeratoma and telangiectasies. The diagnosis was confirmed by leukocyte oligosaccharide enzyme analysis.
\end{abstract}

\section{Keywords}

\section{Angiokeratoma; Telangiectasies; Child; Fucosidosis}

\section{Background}

Fucosidosis is a rare autosomal recessive lysosomial storage disease resulting from $\alpha$-L-fucosidase deficiency [1]. Multiple angiokeratoma is the main dermatological feature of Fucosidosis [2]. We report a new case of fucosidosis with variable dermatological signs: angiokeratomas, telangiectasies and nail bands.

\section{Case Report}

A boy aged 4 years, born of a consanguineous couple, hospitalized for several times with recurrent chest infections since 18 months. He has a family history of mental retardation in the brother in whom an oligosaccharidosis was suspected but not confirmed as he died at 5 years.

*Corresponding author.

How to cite this paper: Jihene, B., et al. (2014) Diagnosis of Fucosidosis through Cutaneous Manifestations. Open Journal of Pediatrics, 4, 76-78. http://dx.doi.org/10.4236/ojped.2014.41010 
Clinical examination of our patient revealed a failure to thrive with statural retardation, a coarse face, an enlarged spleen and delayed motor development. Skin examination showed widespread telangiectasies predominantly on palms, soles and eyelids. There were also distal purple nail bands (Figure 1) and many firm purple papules with hyperkeratosis covering the scrotum corresponding to angiokeratomas (Figure 2). These signs were observed since the age of 18 months and progressively increased with age.

This clinical presentation leads us to suspect a lysosomial storage disease. Fucosidosis was considered given the dermatological features. Laboratory findings confirmed $\alpha$-L-fucosidase deficiency. The child's mother showed a low $\alpha$-L-fucosidase activity suggesting a heterozygous state.

\section{Discussion}

Fucosidosis (MIM 230000) is a rare autosomal recessive lysosomial storage disease due to $\alpha$-L-fucosidase deficiency resulting in multisystem accumulation of oligosaccharides and shingoglycolipids. The disease presents with progressive mental retardation, motor deterioration, coarse facies, growth retardation, recurrent respiratory infections, dysostosis, visceromegaly and seizure [2]-[4].

Variable skin abnormalities are reported in the literature. The most frequent dermatological features of fucosidosis are angiokeratomas and telangiectaies [3], which were both present in our patient.

For a long time, angiokeratomas and particularly angiokeratoma corporis diffusum (ACD) were associated with fabry disease, however other storage diseases and particularly fucosidosis would be considered [3] [6]. As a matter of fact, ACD is now known to occur in several storage diseases related to deficiencies of enzymes that are involved in the metabolism of glycoprotein, including fucosidosis, sialidosis, and mannosidosis [5] [6].

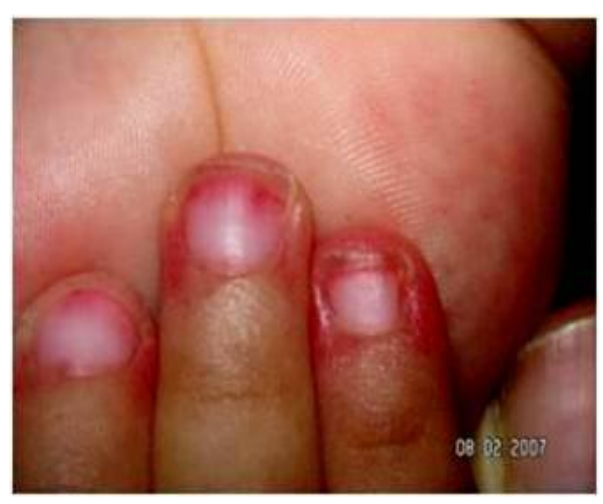

Figure 1. Distal transverse purple nail hands.

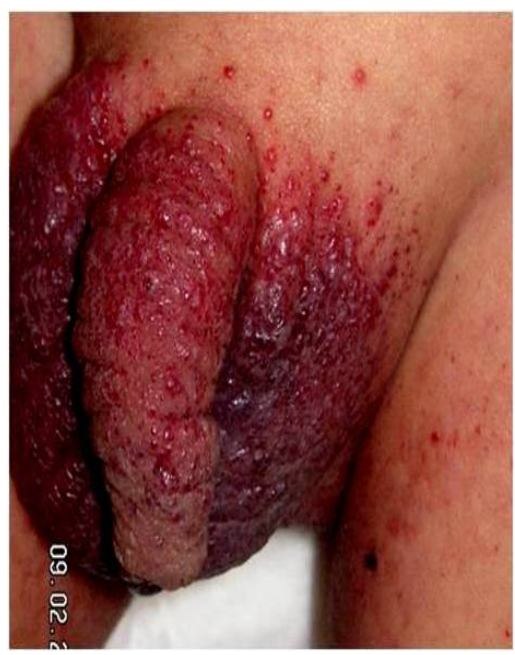

Figure 2. Multiple angiokeratomas on the scrotum and penis. 
These lesions usually occur on the lower region of the trunk, buttocks, and thighs and are usually associated with an underlying enzyme deficiency in the metabolism of glycoprotein [6], as seen in our patient.

The presence of angiokeratomas is correlated to intermediate forms of fucosidosis, and they become more common with increasing age [3] [4].

Other signs are rare, for instance, distal nail band [3], observed in our patient. In the series reported by Ben Turkia et al. [4], these nail bands were present in 2 patients. This distinct feature may arise from subungual telangiectaises or angiokeratomas of the distal nail bed [3]. There are case reports of it occurring even in normal individuals [5] [6].

Although ACD can rarely occur in patients with normal enzymes, it is important to look for enzyme deficiencies other than fabry's disease and particularly fucosidosis.

Conflicts of interests: none.

\section{References}

[1] Pahwa, P., Meena, D., Tanveer, N., Sharma, V.K. and Sethuraman, G. (2012) Punctate Vascular Papules on the Tongue and Scrotum. Indian Journal of Dermatology, 57, 228-229.

[2] Kanitakis, J., Allombert, C., Doebelin, B., et al. (2005) Fucosidosis with Angiokeratoma. Immunohistochimical and Electron, Icroscopic Study of a New Case and Literature Review. Journal of Cutaneous Pathology, 32, 506-511. http://dx.doi.org/10.1111/j.0303-6987.2005.00366.x

[3] Fleming, C., Rennie, A., Fallowfield, M., et al. (1997) Cutaneous Manifestations of Fucosidosis. British Journal of Dermatology, 136, 594-597. http://dx.doi.org/10.1111/j.1365-2133.1997.tb02149.x

[4] Ben Turkia, H., Tebib, N., Azzouz, H., et al. (2008) Phenotypic Spectrum of Fucosidosis in Tunisia. Journal of Inherited Metabolic Disease, 31, S313-S316. http://dx.doi.org/10.1007/s10545-008-0891-0

[5] George, S. and Graham-Brown, R.A. (1994) Angiokeratoma Corporis Diffusum in Fucosidosis. Journal of the Royal Society of Medicine, 87, 707.

[6] Kelly, B. and Kelly, E. (2006) Angiokeratoma Corporis Diffusum in a Patient with No Recognizable Enzyme Abnormalities. Archives of Dermatology, 142, 615-618. http://dx.doi.org/10.1001/archderm.142.5.615 